\title{
Identifying Responders and Exploring Mechanisms of Action of the Endobronchial Coil Treatment for Emphysema
}

\author{
Jorine E. Hartman ${ }^{a}$ Karin Klooster ${ }^{a}$ Sonja W.S. Augustijn ${ }^{a}$ \\ Wouter H. van Geffen ${ }^{b}$ Justin L. Garnerc, d, e Pallav L. Shahc, d, e \\ Nick H.T. Ten Hacken ${ }^{a}$ Dirk-Jan Slebos ${ }^{a}$
}

aDepartment of Pulmonary Diseases and Groningen Research Institute for Asthma and COPD, University Medical Center Groningen, University of Groningen, Groningen, The Netherlands; ${ }^{b}$ Department of Pulmonary diseases,

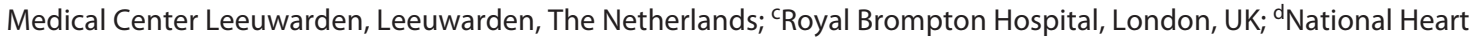

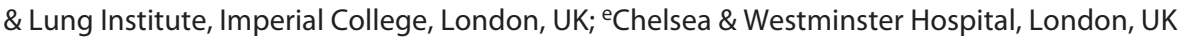

\section{Keywords}

Bronchoscopic lung volume reduction - COPD .

Emphysema

\begin{abstract}
Background: So far, 3 randomized controlled trials have shown that the endobronchial treatment using coils is safe and effective. However, the more exact underlying mechanism of the treatment and best predictors of response are unknown. Objectives: The aim of the study was to gain more knowledge about the underlying physiological mechanism of the lung volume reduction coil treatment and to identify potential predictors of response to this treatment. Methods: This was a prospective nonrandomized single-center study which included patients who were bilaterally treated with coils. Patients underwent an extensive number of physical tests at baseline and 3 months after treatment. Results: Twenty-four patients ( $29 \%$ male, mean age 62 years, forced expiratory volume in $1 \mathrm{~s}\left[\mathrm{FEV}_{1}\right] 26 \%$ pred, residual volume (RV) $231 \%$ pred) were included. Three months after treat-
\end{abstract}

ment, significant improvements were found in spirometry, static hyperinflation, air trapping, airway resistance, treated lobe RV and treated lobes air trapping measured on CT scan, exercise capacity, and quality of life. The change in RV and airway resistance was significantly associated with a change in $\mathrm{FEV}_{1}$, forced vital capacity, air trapping, maximal expiratory pressure, dynamic compliance, and dynamic hyperinflation. Predictors of treatment response at baseline were a higher RV, larger air trapping, higher emphysema score in the treated lobes, and a lower physical activity level. Conclusions: Our results confirm that emphysema patients benefit from endobronchial coil treatment. The primary mechanism of action is decreasing static hyperinflation with improvement of airway resistance which consequently changes dynamic lung mechanics. However, the right patient population needs to be selected for the treatment to be beneficial which should include patients with severe lung hyperinflation, severe air trapping, and significant emphysema in target lobes. (c) 2021 The Author(s)

Published by S. Karger AG, Basel karger@karger.com www.karger.com/res

Karger $\stackrel{\text { ' }}{5}$

GOPEN ACCESS
(C) 2021 The Author(s)

Published by S. Karger AG, Basel

This is an Open Access article licensed under the Creative Commons Attribution-NonCommercial-4.0 International License (CC BY-NC) (http://www.karger.com/Services/OpenAccessLicense), applicable to the online version of the article only. Usage and distribution for commercial purposes requires written permission.
Jorine E. Hartman

Department of Pulmonary Diseases AA11, University Medical Center Groningen PO Box 30001

NL-9700 RB Groningen (The Netherlands)

j.hartman@umcg.nl 


\section{Introduction}

Emphysema is characterized by gradual destruction of alveolar walls. This results in reduced lung elasticity and recoil pressures and allows the smaller airways to collapse prematurely during exhalation, resulting in hyperinflation, air trapping, and diaphragm flattening [1]. In the past decade, less invasive bronchoscopic treatments have been developed, and the lung volume reduction coil (LVRC) is one of those approaches [2].

Currently, 3 randomized controlled trials have been performed which showed that the coil treatment was safe and effective [3-5]. However, the exact underlying working mechanism of the coil treatment is unknown. The proposed mechanism of action is that the compression of the lung parenchyma by the coils reduces air flow to treated portions of the lung, allowing enhanced airflow to healthier untreated portions of the lung. Recently, we found that the reduction in lobar residual volume (RV) was the driving mechanism of action [6]. This lobar compression also reduces the volume of the hyperinflated emphysematous lung, resulting in lung volume reduction with possible improved diaphragmatic efficiency. Additionally, by gathering up the loose parenchyma of the most severely damaged segments, the coil may restore elasticity and recoil to the whole lung, improving expiratory flow rates, reducing small airway collapse with subsequent air trapping, and reducing dynamic hyperinflation. Therefore, to advance the understanding of changes in lung physiology, it would be very useful to investigate

Table 1. Baseline characteristics and change after 3-month follow-up $(n=24)$

\begin{tabular}{lcccc}
\hline Variable & Baseline & 3 months FU & Difference & $p$ value \\
\hline Male, $n(\%)$ & $7(29)$ & - & - & - \\
Age, years & $62.0 \pm 6.9$ & - & - & - \\
Pack years, $n$ & $31.5(9-144)$ & - & - & - \\
Exacerbations past year, $n$ & $1.5 \pm 1.2$ & - & - & - \\
FEV, L & $0.66 \pm 0.17$ & $0.78 \pm 0.19$ & 0.12 & $<0.001$ \\
FVC, L & $2.54 \pm 0.64$ & $2.95 \pm 0.77$ & 0.41 & $<0.001$ \\
RV, L & $4.85 \pm 0.99$ & $4.30 \pm 0.75$ & -0.55 & $<0.001$ \\
TLC difference BB-HE, L & $0.78(0.10-2.45)$ & $0.62(-0.35$ to 1.42$)$ & -0.38 & 0.015 \\
DLCO, mmol/L/kPa & $2.33 \pm 0.73$ & $2.41 \pm 0.70$ & 0.09 & 0.254 \\
VA/TLC, \% & $54.86 \pm 6.50$ & $59.0 \pm 4.52$ & 4.14 & 0.001 \\
MIP, kPa & $7.18 \pm 1.51$ & $7.66 \pm 1.50$ & 0.48 & 0.087 \\
MEP, kPa & $7.55 \pm 2.15$ & $7.47 \pm 2.22$ & -0.08 & 0.791 \\
Compliance dynamic, L/kPa & $1.94 \pm 0.83$ & $2.25 \pm 1.21$ & 0.31 & 0.104 \\
Compliance static, L/kPa & $4.33 \pm 1.54$ & $4.58 \pm 1.92$ & 0.25 & 0.42 \\
Raw, kPa s/L & $0.81(0.56-2.20)$ & $0.80(0.41-1.51)$ & -0.14 & 0.021 \\
IC delta MPT, L & $-0.95 \pm 0.25$ & $-1.02 \pm 0.28$ & -0.075 & 0.074 \\
6MWD, m & $341 \pm 77$ & $372 \pm 70$ & 33 & 0.001 \\
$W_{\text {max, W }}$ & $27 \pm 12$ & $34 \pm 10$ & 6.4 & $<0.001$ \\
VO ${ }_{2 m a x}$, mL & $695(508-1,090)$ & $727(546-1,109)$ & 42 & 0.131 \\
Physical activity, steps per day & $2,364(549-6,996)$ & $2,506(737-7,452)$ & 189 & 0.475 \\
SGRQ, total score & $56.0 \pm 9.8$ & $46.4 \pm 11.7$ & -9.7 & 0.001 \\
Perfusion treated lobes, \% & $34.6 \pm 12.2$ & $35.5 \pm 23.3$ & 0.83 & 0.548 \\
Air trapping treated lobes, L & $1.96(1.21-3.42)$ & $1.71(1.01-3.30)$ & -0.34 & 0.001 \\
RV treated lobes, L & $2.28(1.53-3.74)$ & $2.10(1.29-3.54)$ & -0.28 & 0.004 \\
Emphysema score treated lobes, \% & $45.9 \pm 10.8$ & - & - & - \\
Airway radius treated lobes, mm & $1.12 \pm 0.24$ & $1.11 \pm 0.22$ & -0.007 & 0.911 \\
\hline & & & & \\
\hline
\end{tabular}

Data are presented as $n(\%)$, mean \pm standard deviation or median (range). Difference between baseline and 3-month follow-up were tested with a paired $t$ test or Wilcoxon signed rank test. Significant differences $(p<0.05)$ are depicted in bold. FU, follow-up; $\mathrm{FEV}_{1}$, forced expiratory volume in $1 \mathrm{~s}$; FVC, forced vital capacity; RV, residual volume; TLC, total lung capacity; DLCO, diffusion capacity for carbon monoxide; VA, alveolar volume; MIP, maximal inspiratory pressure; MEP, maximal expiratory pressure; Raw, effective airway resistance; IC, inspiratory capacity; MPT, metronome paced test; $6 \mathrm{MWD}$, 6-min walk distance; $W_{\max }$, maximal wattage; $\mathrm{VO} 2_{\max }$, maximal oxygen uptake; SGRQ, St. George’s Respiratory Questionnaire; mmol, millimol; L, liter; kPa, kilopascal; $\mathrm{s}$, second; mm, millimeter. 
dynamic hyperinflation, compliance/elastic recoil, diaphragm functioning, ventilation and small airways/air trapping parameters more in depth in patients who are treated with LVRCs.

Another less well-understood aspect of the LVRC treatment is which group of patients benefits of this treatment. So far, a clinical significant response to the coil treatment has been reported in about 5-6 of every 10 patients treated [7]. To maximize the responder rate and avoid unnecessary treatments, it would be very useful if we could identify the responders beforehand. Recently, the correct choice of the most destructed target lobes to treat, significant hyperinflation ( $R V \geq 200 \%$ of predicted), emphysema score $>20 \%$ low attenuation area at -950 Hounsfield units, and absence of airway disease were found to be predictors of better response [8]. Therefore, the aim of this study was to gain more knowledge on the underlying physiological mechanism of the LVRC treatment and to identify potential predictors of response to this treatment.

\section{Methods}

\section{Study Population}

This was a prospective nonrandomized intervention study ("REACTION-study": NCT02179125) including symptomatic patients with severe emphysema (forced expiratory volume in $1 \mathrm{~s}\left[\mathrm{FEV}_{1}\right] \%$ pred $<45 \%$, RV\% pred $>175 \%$ ) between March 9, 2015 and July 4, 2018. The study was originally designed as a multicenter trial but due to regulatory issues in the UK performed as 2 separate trials. The complete list of inclusion and exclusion criteria can be found in the online suppl. Table 1; see www.karger.com/doi/10.1159/000514319 for all online suppl. material. Patients were included in the analyses when they were bilaterally treated and visited our hospital for the study tests at baseline and 3 months after the second treatment. The study was approved by the Local Medical Ethics Committee (METc\#2014.447), and all patients provided informed consent.

\section{Study Procedure}

Patients visited our hospital for the study measurements described below at baseline and at 3 months after the second treatment. After screening, patients underwent the first coil treatment and 6-8 weeks later the second treatment. The coils were placed in the most damaged lobes per lung based on a visual CT analysis by the treating physician.
Fig. 1. Study flowchart. RV, residual volume; 6MWD, 6-min walk distance; TLC, total lung capacity.

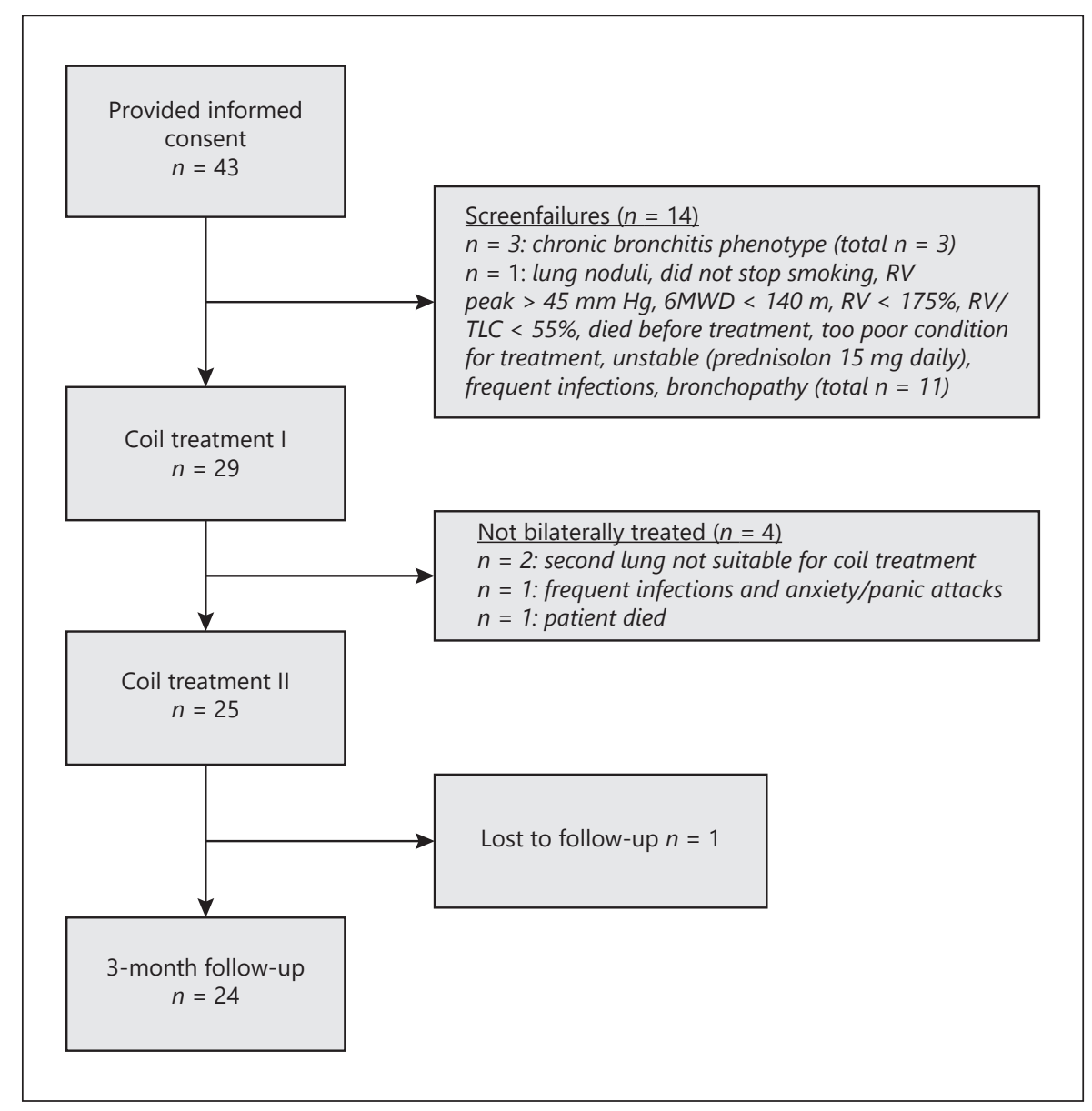


Table 2. Overview of all reported (serious) adverse events $(n=29)$

\begin{tabular}{|c|c|c|c|c|}
\hline Adverse event & $\begin{array}{l}\text { Events, } \\
n\end{array}$ & Time & $\begin{array}{l}\text { Duration, } \\
\text { days }\end{array}$ & $\begin{array}{l}\text { Relationship } \\
\text { with treatment }\end{array}$ \\
\hline \multicolumn{5}{|l|}{ Serious adverse events } \\
\hline \multirow{5}{*}{ COPD exacerbation } & \multirow{5}{*}{6} & 24 days after TX 1 & 12 & Not \\
\hline & & 67 days after TX 1 & 11 & Not \\
\hline & & 70 days after TX 2 & 6 & Not \\
\hline & & 74 days after TX 2 & 37 & Possible \\
\hline & & 131 days after TX 2 & 15 & Not \\
\hline \multirow[t]{2}{*}{ Pneumonia } & \multirow[t]{2}{*}{2} & 14 days after TX 2 & 32 & Probably \\
\hline & & 104 days after TX 2 & 4 & Not \\
\hline Pneumothorax & 1 & 163 days after TX 2 & 4 & Not \\
\hline Respiratory failure & 1 & 43 days after TX 1 & 12 & Not \\
\hline Respiratory failure leading to death* & 1 & 84 days after TX 1 & 2 & Not \\
\hline $\begin{array}{l}\text { Nonserious adverse events } \\
\text { COPD exacerbation }\end{array}$ & 5 & & & \\
\hline Hemoptysis & 2 & & & \\
\hline Increased dyspnea & 2 & & & \\
\hline Pyelonephritis & 1 & & & \\
\hline Chest pain & 1 & & & \\
\hline
\end{tabular}

TX, treatment. * Progressive hypercapnic respiratory failure due to disease progression. No signs of infection, consolidation, or coil-associated opacity. After final episode, it was decided to start palliative care, therefore deemed as not related.

\section{Study Measurements}

Spirometry, body plethysmography, helium dilution, and diffusion capacity for carbon monoxide (DLCO) were performed according to the ATS/ERS guidelines [9-11]. An esophageal balloon was used to measure static and dynamic lung compliance (CooperSurgical, Berlin, Germany). Furthermore, maximal inspiratory pressure and maximal expiratory pressure (MEP) were measured using body plethysmography $[12,13]$ and dynamic hyperinflation with a metronome-paced test (used protocol is described in reference [14]). Exercise capacity was measured by a 6-minute walk distance (6MWD) test and an incremental cycle ergometry test according to the ATS guidelines $[15,16]$. Physical activity was measured for 1 week by the Dynaport Movemonitor (McRoberts, Hague, The Netherlands) [17]. St. George's Respiratory Questionnaire (SGRQ) was administered to measure quality of life [18]. Lung perfusion was measured by a perfusion scan using $99 \mathrm{mTc}$ albumin. An inspiratory and expiratory high-resolution computed tomography scan was performed, and quantitative analyses were performed by FLUIDDA Inc., (Kontich, Belgium). Outcomes were lobar volumes, emphysema destruction scores, airway radius, and air trapping (defined as all intrapulmonary voxels between $-1,024$ and -850 Hounsfield units, on the expiratory high-resolution computed tomography scan). Furthermore, on CT scan, a blinded visual assessment of the presence or absence of coil-associated opacity (CAO) was performed by DJS.

\section{Statistical Analyses}

All analyses were performed with IBM-SPSS statistics version 23(IBM, Armonk, NY, USA). $p$ values $<0.05$ were considered statistically significant. Safety was reported by the number and type of adverse events. A paired $t$ test (normally distributed data) or a Wilcoxon signed rank test (non-normal data distribution) was performed to investigate the difference between baseline and 3-month follow-up in all clinical variables. To calculate the number of responders, we used the following established minimal important differences: $\mathrm{FEV}_{1}: 100 \mathrm{~mL}$ [19], RV: $310 \mathrm{~mL}$ [20], 6MWD: 26 m [21], SGRQ: 8 units [22], steps per day: 600 steps [23, 24]. Differences between responders in RV were tested by an independent $t$ test or Mann-Whitney U test (non-normal distributed data). To investigate the mechanism of action, we calculated the association between the change in RV and change in airway resistance with change in other clinical outcomes using Pearson's correlation 


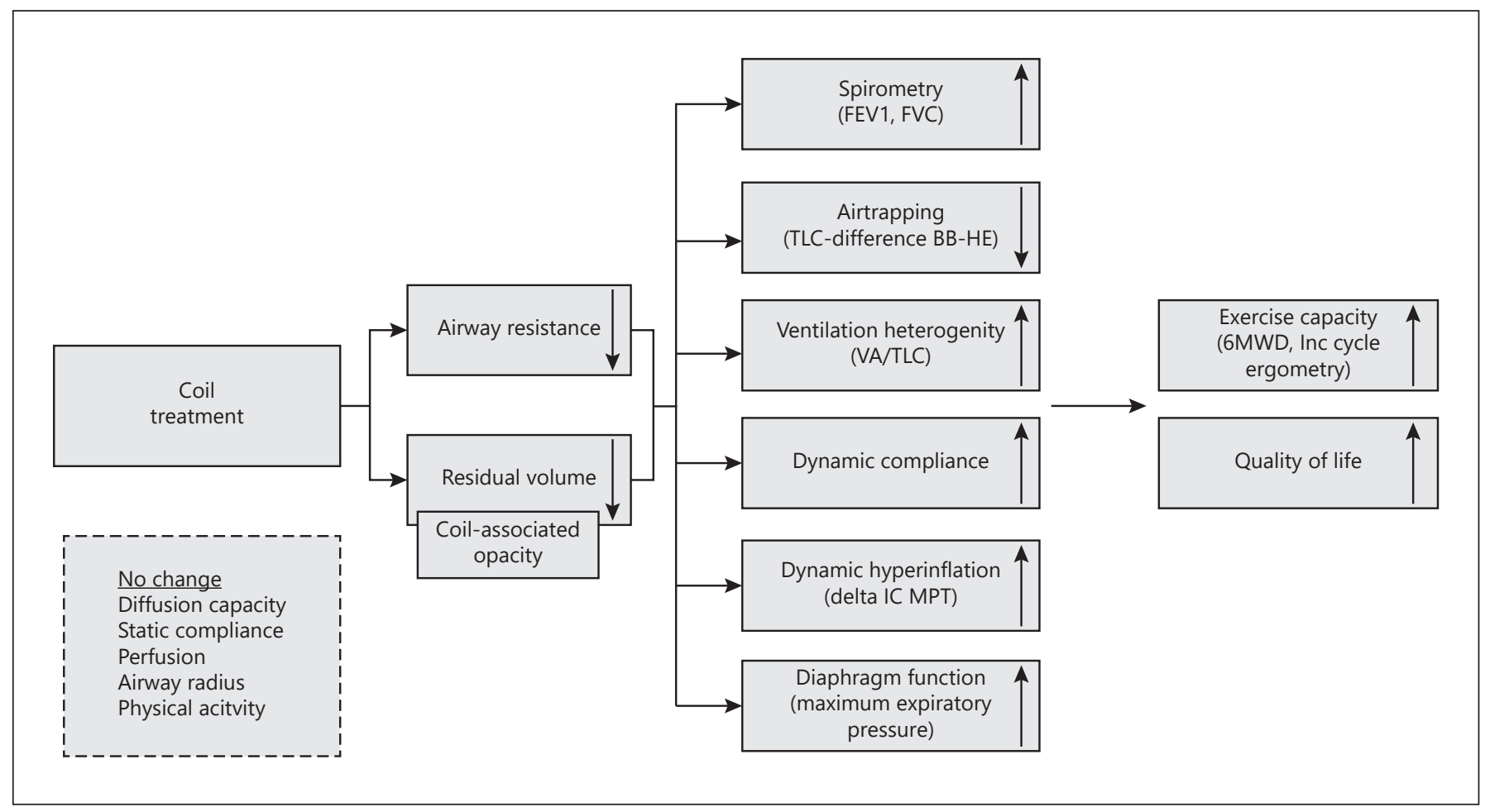

Fig. 2. Schematic overview of the potential mechanism of action of the coil treatment. $\mathrm{FEV}_{1}$, forced expiratory volume in $1 \mathrm{~s}$; FVC, forced vital capacity; TLC, total lung capacity difference; VA, alveolar volume; IC, inspiratory capacity; MPT, metronome paced test; 6MWD, 6-min walk distance; TLC, total lung capacity; MEP, maximal expiratory pressure; CAO, coil-associated opacity.

coefficient or Spearman's rho (non-normal distributed data). Furthermore, we performed an independent $t$ test to investigate whether patients with CAO have better response in clinical outcomes compared to patients without CAO. To investigate the predictors of response, we calculated the association between change in RV and change in airway resistance and potential predictors of response at baseline using Pearson's correlation coefficient or Spearman's rho.

\section{Results}

In total, 24 patients (29\% male, mean age 62 years, $\mathrm{FEV}_{1}$ 26\% pred, RV $231 \%$ pred) were included in the analyses. Patient characteristics can be found in Table 1, with the study flowchart in Figure 1.

\section{Procedure Characteristics and Safety}

Twenty-one patients (88\%) were treated in both upper and 3 patients in both lower lobes. The median procedure time was 35 (range: $20-90$ ) min, and the median number of coils placed was 21.5 (19-25) (right lung: 11 [9-13], left lung: $11[10-12])$. Median time between treatments was
48 (35-63) days. All reported (serious) adverse events of all patients treated unilaterally or bilaterally $(n=29)$ can be found in Table 2. In total, 11 serious adverse events occurred during the study period, of which 3 were probably or possibly related to the treatment (2 COPD exacerbations and 1 pneumonia). One patient died 84 days after the first treatment due to progressive hypercapnic respiratory failure secondary to disease progression which was not deemed to be related to the treatment.

\section{Efficacy}

Changes between baseline and 3-month follow-up for all clinical variables can be found in Table 1 . Significant improvements were found in spirometry $\left(\mathrm{FEV}_{1}\right.$ and forced vital capacity [FVC]), static hyperinflation, air trapping (measured by the total lung capacity (TLC) difference between helium and body plethysmography), airway resistance, treated lobes RV and treated lobes air trapping (both measured on CT scan), exercise capacity (6MWD and cycle ergometry), and quality of life (SGRQ). No significant changes were found in DLCO, maximal inspiratory pressure and MEP, lung compliance, dynam- 
Table 3. Association between change in RV or airway resistance and change in clinical outcomes $(n=24)$

\begin{tabular}{|c|c|c|}
\hline & $\Delta \mathrm{RV}$ & $\Delta$ raw \\
\hline$\Delta \mathrm{FEV}_{1}, \mathrm{~L}$ & -0.631 & $-0.508^{*}$ \\
\hline$\Delta \mathrm{FVC}, \mathrm{L}$ & -0.754 & $-0.505 *$ \\
\hline$\Delta \mathrm{RV}, \mathrm{L}$ & - & $0.715^{*}$ \\
\hline$\Delta$ TLC difference, $\mathrm{L}$ & $0.676^{*}$ & $0.410^{*}$ \\
\hline$\Delta \mathrm{DLCO}, \mathrm{mmol} / \mathrm{L} / \mathrm{kPa}$ & -0.303 & $-0.194^{*}$ \\
\hline$\Delta \mathrm{VA} / \mathrm{TLC}, \%$ & -0.537 & $-0.565^{*}$ \\
\hline$\Delta \mathrm{MIP}, \mathrm{kPa}$ & -0.357 & $-0.326^{*}$ \\
\hline$\triangle \mathrm{MEP}, \mathrm{kPa}$ & -0.421 & $-0.586^{*}$ \\
\hline$\Delta$ compliance dynamic, $\mathrm{L} / \mathrm{kPa}$ & -0.793 & $-0.781 *$ \\
\hline$\Delta$ compliance stat, $\mathrm{L} / \mathrm{kPa}$ & -0.122 & $-0.154^{*}$ \\
\hline$\Delta$ raw, $\mathrm{kPa} s / \mathrm{L}$ & 0.697 & - \\
\hline$\Delta$ IC delta MPT, $\mathrm{L}$ & 0.528 & $0.503 *$ \\
\hline$\Delta$ perfusion treated lobes, $\%$ & 0.015 & $-0.175^{*}$ \\
\hline$\Delta$ air trapping treated lobes, $\mathrm{L}$ & 0.313 & $0.073^{*}$ \\
\hline$\Delta \mathrm{RV}$ treated lobes, $\mathrm{L}$ & 0.320 & $0.081^{*}$ \\
\hline$\Delta$ airway radius treated lobes, $\mathrm{mm}$ & 0.117 & $-0.186^{*}$ \\
\hline
\end{tabular}

Data are presented as Pearson correlation coefficient or* Spearman's rho. Significant associations $(p<0.05)$ are depicted in bold. $\Delta$ : change between baseline and 3-month follow-up. $\Delta$ Raw was measured with an esophageal balloon. $\mathrm{FEV}_{1}$, forced expiratory volume in $1 \mathrm{~s}$; FVC, forced vital capacity; RV, residual volume; TLC, total lung capacity; DLCO, diffusion capacity for carbon monoxide; VA, alveolar volume; MIP, maximal inspiratory pressure; MEP, maximal expiratory pressure; Raw, effective airway resistance; IC, inspiratory capacity; MPT, metronome paced test; mmol, millimol; L, liter; $\mathrm{kPa}$, kilopascal; s, second; mm, millimeter.

ic hyperinflation, lung perfusion, physical activity, and airway radius. The responder rates were $\mathrm{RV}: 67 \%, \mathrm{FEV}_{1}$ : 46\%, 6MWD: $48 \%$, SGRQ: $58 \%$, and steps/day: $33 \%$. The responders based on RV had a significant better improvement than the nonresponders in FVC, air trapping (measured by the TLC difference between helium and body plethysmography), alveolar volume/TLC, MEP, dynamic compliance, airway resistance, and exercise capacity (cycle ergometry) (online suppl. Table 2).

\section{Mechanism of Action}

The change in RV and airway resistance was significantly associated with a change in $\mathrm{FEV}_{1}, \mathrm{FVC}$, air trapping (TLC difference between body plethysmography and helium), MEP, dynamic compliance, and dynamic hyperinflation (Table 3 ). In 15 patients (62.5\%), CAO was visible on the $\mathrm{CT}$ thorax. Patients with $\mathrm{CAO}$ experienced greater improvement after treatment in $\mathrm{FEV}_{1}, \mathrm{FVC}, \mathrm{RV}$, dynamic and static compliance, and 6MWD than patients without CAO (Table 4; online suppl. Table 3).

\section{Predictors of Response}

A larger decrease in RV in response to the LVRC treatment was significantly associated with the following clinical variables at baseline: a higher RV (measured by body plethysmography and on CT scan), larger air trapping (measured on CT scan and the TLC difference between body plethysmography and helium dilution), higher treated lobes emphysema score, and lower physical activity level (Table 5; online suppl. Table 4).

\section{Discussion}

This study aimed to gain more knowledge on the underlying physiological mechanism and potential predictors of response to the LVRC treatment. Consequently, patients underwent a large number of physiological measurements before and after treatment. Our results showed that patients can benefit from the treatment in wellknown domains like static hyperinflation, exercise capacity, and quality of life but also in lesser known domains, notably air trapping and airway resistance. Furthermore, both a decrease in airway resistance and RV was significantly associated with an improvement in spirometry, air trapping, ventilation heterogeneity, dynamic compliance, dynamic hyperinflation, and diaphragm function. At baseline, more severe static hyperinflation, more air trapping, more severe emphysema destruction in the treatment target lobes, and a lower physical activity level were predictors of successful LVRC treatment.

In accordance with multiple previous studies, we found that the LVRC treatment had an acceptable safety profile and led to significant improvements in lung function, static hyperinflation, exercise capacity, and quality of life $[3-5,7,25,26]$. We investigated a broad range of clinical outcomes, some of them for the first time, whereas others were previously tested in small case series. For example, we found for the first time significant improvements in air trapping, both measured with body plethysmography and using quantitative CT scan analysis, as well as maximal exercise capacity measured by incremental cycle ergometry. The significant change in airway resistance was in line with 2 smaller previous studies [27, 28]. In contrast, we did not find significant improvements in DLCO, dynamic hyperinflation, inspiratory and expiratory muscle strength, lung compliance, lung perfusion, airway radius measured on CT scan, and physical activity. Opposite to our results, Makris et al. [29] found a significant decrease in dynamic compliance in a small group of patients $(n=10)$ compared with controls $(n=11)$. The 
Table 4. Significant differences between patients with or without visible CAO

\begin{tabular}{lccc}
\hline & $\begin{array}{l}\text { CAO present } \\
(n=15)\end{array}$ & $\begin{array}{l}\text { CAO not-present } \\
(n=9)\end{array}$ & $p$ value \\
\hline$\Delta \mathrm{FEV}_{1}, \mathrm{~L}$ & $0.16 \pm 0.09$ & $0.05 \pm 0.06$ & $\mathbf{0 . 0 0 4}$ \\
$\Delta \mathrm{FVC}, \mathrm{L}$ & $0.55 \pm 0.40$ & $0.18 \pm 0.18$ & $\mathbf{0 . 0 0 6}$ \\
$\Delta \mathrm{RV}, \mathrm{L}$ & $-0.70 \pm 0.45$ & $-0.30 \pm 0.14$ & $\mathbf{0 . 0 0 5}$ \\
$\Delta$ compliance dynamic, $\mathrm{L} / \mathrm{kPa}$ & $0.66 \pm 0.91$ & $-0.30 \pm 0.40$ & $\mathbf{0 . 0 0 2}$ \\
$\Delta$ compliance static, L/kPa & $0.73 \pm 1.25$ & $-0.57 \pm 1.50$ & $\mathbf{0 . 0 3 1}$ \\
$\Delta$ 6MWD, m & $44 \pm 45$ & $12 \pm 27$ & $\mathbf{0 . 0 4 8}$ \\
\hline
\end{tabular}

Data are presented as mean change \pm standard deviation. Difference between patients with or without CAO was tested with an independent $t$ test. Significant differences $(p<$ 0.05 ) are depicted in bold. $\Delta$, change between 3 -month follow-up and baseline; CAO, coilassociated opacity; $\mathrm{FEV}_{1}$, forced expiratory volume in $1 \mathrm{~s} ; \mathrm{FVC}$, forced vital capacity; RV, residual volume; 6MWD, 6-min walk distance; L, liter; kPa, kilopascal.
Table 5. Significant association between change in RV and potential predictors of response at baseline

\begin{tabular}{lcc}
\hline & $\Delta \mathrm{RV}, \mathrm{L}$ & $p$ value \\
\hline $\mathrm{RV}, \mathrm{L}$ & $-\mathbf{0 . 7 2 5}$ & $<\mathbf{0 . 0 0 1}$ \\
TLC difference BB-HE, L & $-\mathbf{0 . 5 1 6}$ & $\mathbf{0 . 0 1}$ \\
Physical activity, steps per day & $\mathbf{0 . 4 9 2}$ & $\mathbf{0 . 0 1 5}$ \\
Air trapping treated lobes, L & $-\mathbf{0 . 6 0 0}$ & $\mathbf{0 . 0 0 2}$ \\
RV treated lobes, L & $-\mathbf{0 . 6 2 3}$ & $\mathbf{0 . 0 0 2}$ \\
Emphysema score treated lobes, \% & $-\mathbf{0 . 4 1 4}$ & $\mathbf{0 . 0 4 4}$ \\
\hline
\end{tabular}

Data are presented in Pearson correlation coefficient or* Spearman's rho. Significant associations $(p<0.05)$ are depicted in bold. $\Delta$, change between baseline and 3-month follow-up; RV, residual volume; TLC, total lung capacity.

nonsignificant change in physical activity was in line with our previous pilot study [30] but not with a recent published pilot study [31]. This difference could be caused by the extreme low baseline physical activity levels in the other study, with only 2 days of measurement compared to 7 and the shorter follow-up after coil treatment (6 vs. 12 weeks). We also did not find a change in perfusion in the (un)treated lobes, while Lador et al. [32] did find an improvement in perfusion in the untreated lobes after treatment. This difference could be caused by the fact that they measured perfusion by dual-energy computed tomography.

Figure 2 shows a schematic overview of the potential mechanism of action based on our results. We found that both a decrease in airway resistance and RV was associated with a significant change in $\mathrm{FEV}_{1}$ and $\mathrm{FVC}$, air trapping, ventilation heterogeneity, dynamic compliance, dynamic hyperinflation, and diaphragm function. Our re- sults confirm previous studies that have shown that the LVRC treatment leads to reduction of the lung volume, which can lead to clinical benefits [6,27]. It seems that the primary driver of action is the actual lung volume reduction, together with an accompanied decrease in airway resistance. Consequently, the decrease in RV can lead to an increase in vital capacity and the inspiratory capacity, which increased the ability to develop dynamic hyperinflation. This suggests that the coil treatment does not directly improve the elasticity and recoil of the lung but that the lung mechanics change due to the reduction in lung volume and airway resistance. It could be that due to the stiffness of the current coil design, the coil is not able to reduce the elasticity. Future trials using new to be designed coils with greater intrinsic flexibility should show whether these can lead to a direct improvement in elasticity and recoil. Our results also showed that patients in whom CAO was visible had additional benefits compared to patients who did not, which is in line with results from the RENEW study [4]. It seems that these reactive changes are associated with compression of the surrounding parenchyma and therefore contributes to volume reduction in the treated lobe.

We found that greater static hyperinflation, more air trapping, higher emphysema destruction score, and a lower physical activity level at baseline were significantly associated with a larger improvement in RV after treatment. Higher static hyperinflation and emphysema destruction as predictors of response are in line with a recent publication [8]. In addition to this, we have also found larger air trapping (measured on CT scan and the TLC difference between body plethysmography and helium dilution) at baseline to be a possible predictor of response. Furthermore, the RENEW post hoc study did demonstrate the 
negative influence of the presence of airway disease on treatment outcome. However, in the present study, we did not enroll patients with severe airway disease, and therefore, this could not be evaluated in our analyses as a potential predictor. Combining both results show that it is important to only treat patients who have severe lung hyperinflation and emphysema. In that perspective, our inclusion criterion of a RV below $175 \%$ of predicted was probably too low, as reflected by our responder rates of $33-58 \%$. It would be interesting to establish a cutoff value of $\mathrm{RV}$ as an indicator of response, but unfortunately, our sample size was too low for this kind of analysis. Significant air trapping could be added to these predictors of response, which can be measured on CT scan or the TLC difference between body plethysmography and helium dilution. The addition of significant air trapping is also in line with the recommendations of an expert panel [2]. A low physical activity level was also a predictor of better response in our population, which is less clear. More severe static hyperinflation could cause a lower level of physical activity. But it could also be an indication that it is important to treat only symptomatic patients with limitations, in line with the general recommendations for bronchoscopic lung volume reduction [33]. However, it is also strange that a low physical activity level was a predictor, while 6-minute walk distance and maximal workload on the cycle ergometer test were not.

Our study has some limitations. The sample size was relatively low, and we did not include a control group. However, 3-coil RCTs did not show any benefit in the control groups 3-12 months after randomization [3-5]. Furthermore, the follow-up was relatively short (3 months), which could have been too short to detect improvements in, for example, physical activity and inspiratory and expiratory muscle strength. A strength of our study is the extensive amount of physiological measurements that have been performed. Consequently, we were able to investigate and combine for the first time a broad range of potential mechanisms of action and predictors of response.

Unfortunately, the future of the coil treatment is uncertain as the current owner of the treatment (Boston Scientific Corp., Marlborough, MA, USA) has decided to discontinue with the treatment. Therefore, it is not known whether patients can still be treated with coils in the future. However, currently, a new generation of the device is developed with an improved design (patent number: US20190328400A1). We believe the results of our study could be applicable to this new-generation device as well, but future research will need to confirm this.
Our results confirm that patients benefit from the bronchoscopic LVRC treatment. Furthermore, it seems that the primary mechanism of action is decreasing static hyperinflation with improvement of airway resistance, which consequently changes dynamic lung mechanics. However, the right patient population needs to be selected for the treatment to be beneficial which should include patients with severe lung hyperinflation, severe air trapping, and severe emphysema in target lobes.

\section{Statement of Ethics}

The study was approved by the Medical Ethics Committee of the University Medical Center Groningen (METc\#2014.447), and all patients provided informed consent. The study was registered in clinicaltrials.gov with number NCT02179125.

\section{Conflict of Interest Statement}

J.E.H., K.K., N.H.T.t.H., S.W.S.A., W.v.G., and J.L.G. have no conflicts of interest to declare. P.S. reports personal fees from Boston Scientific, CSA Medical, Creo Medical, Nuvairia Olympus, Medtronic, and PneumRX/BTG as consultant on scientific advisory board, sponsorship to Imperial College for a bronchoscopy course by from ERBE, Cook medical, Medtronic, Boston Scientific, Broncus, Pulmonx, Olympus, and PneumRX/BTG, all outside the submitted work. He has been an investigator on clinical trials with bronchial thermoplasty, endobronchial valves, endobronchial coils, thermal ablation, and the airway bypass procedure. DJS reports grants, nonfinancial support, and other from Nuvaira Inc., Minneapolis, MN, USA; grants and nonfinancial support from CSA medical, Boston, MA, USA; grants, personal fees, and nonfinancial support from PulmonX Inc., Redwood City, CA, USA; and grants and nonfinancial support from PneumRx/BTG, California, USA, all outside the submitted work.

\section{Funding Sources}

The authors received an unrestricted grant of PneumRx GmbH (Dusseldorf, Germany) which also provided the treatment devices in kind.

\section{Author Contributions}

J.E.H. and D.J.S. contributed to the conception of the study, acquisition of data, and data analyses and wrote the first version of the manuscript. K.K., P.L.S., and NHTtH contributed to the conception of the study and acquisition of data and revised the manuscript. S.W.S.A., W.v.G., and J.L.G. contributed to acquisition of data and revised the manuscript. All authors approved the final version of the manuscript. 


\section{References}

1 Kemp SV, Polkey MI, Shah PL. The epidemiology, etiology, clinical features, and natural history of emphysema. Thorac Surg Clin. 2009;19(2):149-58.

2 Slebos D-J, ten Hacken NH, Hetzel M, Herth FJF, Shah PL. Endobronchial coils for endoscopic lung volume reduction: best practice recommendations from an expert panel. Respiration. 2018;96(1):1-11.

3 Shah PL, Zoumot Z, Singh S, Bicknell SR, Ross ET, Quiring J, et al. Endobronchial coils for the treatment of severe emphysema with hyperinflation (RESET): a randomised controlled trial. Lancet Respir Med. 2013;1(3): 233-40.

4 Sciurba FC, Criner GJ, Strange C, Shah PL, Michaud G, Connolly TA, et al. Effect of endobronchial coils vs usual care on exercise tolerance in patients with severe emphysema: the renew randomized clinical trial. JAMA. 2016;315(20):2178-89.

5 Deslée G, Mal H, Dutau H, Bourdin A, Vergnon JM, Pison C, et al. Lung volume reduction coil treatment vs. usual care in patients with severe emphysema. JAMA. 2016;315(2): 175-84.

6 Hartman JE, Shah PL, Sciurba F, Herth FJF, Slebos DJ; RENEW Study Group. Endobronchial coils for emphysema: dual mechanism of action on lobar residual volume reduction. Respirology. 2020;25(11):1160-6.

7 Slebos DJ, Hartman JE, Klooster K, Blaas S, Deslee G, Gesierich W, et al. Bronchoscopic coil treatment for patients with severe emphysema: a meta-analysis. Respiration. 2015; 90(2):136-45.

8 Slebos DJ, Cicenia J, Sciurba FC, Criner GJ, Hartman JE, Garner J, et al. Predictors of response to endobronchial coil therapy in patients with advanced emphysema. Chest. 2019;155(5):928-37.

9 Wanger J, Clausen JL, Coates A, Pedersen OF, Brusasco V, Burgos F, et al. Standardisation of the measurement of lung volumes. Eur Respir J. 2005 Sep;26(3):511-22.

10 Miller MR, Hankinson J, Brusasco V, Burgos F, Casaburi R, Coates A, et al. Standardisation of spirometry. Eur Respir J. 2005 Aug;26(2): 319-38.

11 MacIntyre N, Crapo RO, Viegi G, Johnson DC, van der Grinten CP, Brusasco V, et al. Standardisation of the single-breath determination of carbon monoxide uptake in the lung. Eur Respir J. 2005;26(4):720-35.
12 Sclauser Pessoa IM, Franco Parreira V, Fregonezi GA, Sheel AW, Chung F, Reid WD. Reference values for maximal inspiratory pressure: a systematic review. Can Respir J. 2014;21(1):43-50.

13 Laveneziana P, Albuquerque A, Aliverti A, Babb T, Barreiro E, Dres M, et al. ERS statement on respiratory muscle testing at rest and during exercise. Eur Respir J. 2019;53(6): 1801214.

14 Klooster K, Ten Hacken NH, Hartman JE, Sciurba FC, Kerstjens HA, Slebos DJ. Determining the role of dynamic hyperinflation in patients with severe chronic obstructive pulmonary disease. Respiration. 2015;90(4):30613.

15 ATS Committee on Proficiency Standards for Clinical Pulmonary Function Laboratories. ATS statement: guidelines for the six-minute walk test. Am J Respir Crit Care Med. 2002 Jan;166(1):111-7.

16 American Thoracic Society; American College of Chest Physicians. ATS/ACCP statement on cardiopulmonary exercise testing. Am J Respir Crit Care Med. 2003;167(2):21177.

17 Rabinovich RA, Louvaris Z, Raste Y, Langer D, Van Remoortel H, Giavedoni S, et al. Validity of physical activity monitors during daily life in patients with COPD. Eur Respir J. 2013;42(5):1205-15

18 Jones PW, Quirk FH, Baveystock CM, Littlejohns P. A self-complete measure of health status for chronic airflow limitation. The St. George's respiratory questionnaire. Am Rev Respir Dis. 1992;145(6):1321-7.

19 Donohue JF. Minimal clinically important differences in COPD lung function. COPD. 2005;2(1):111-24.

20 Hartman JE, Ten Hacken NH, Klooster K, Boezen HM, De Greef MH, Slebos DJ. The minimal important difference for residual volume in patients with severe emphysema. Eur Respir J. 2012;40(5):1137-41.

21 Puhan MA, Chandra D, Mosenifar Z, Ries A, Make B, Hansel NN, et al. The minimal important difference of exercise tests in severe COPD. Eur Respir J. 2011;37(4):784-90.

22 Welling JBA, Hartman JE, Ten Hacken NHT, Klooster K, Slebos D-J. The minimal important difference for the St George's respiratory questionnaire in patients with severe COPD. Eur Respir J. 2015;46(6):1598-604.

23 Demeyer H, Burtin C, Hornikx M, Camillo CA, Van Remoortel H, Langer D, et al. The minimal important difference in physical activity in patients with COPD. PLoS One. 2016; 11(4):e0154587.
24 Teylan M, Kantorowski A, Homsy D, Kadri R, Richardson C, Moy M. Physical activity in COPD: minimal clinically important difference for medical events. Chron Respir Dis. 2019 Jan-Dec; 16:1479973118816424-9.

25 Zoumot Z, Kemp SV, Singh S, Bicknell SR, McNulty WH, Hopkinson NS, et al. Endobronchial coils for severe emphysema are effective up to 12 months following treatment medium term and cross-over results from a randomised controlled trial. PLoS One. 2015; 10(4):e0122656.

26 Slebos DJ, Klooster K, Ernst A, Herth FJF, Kerstjens HAM. Bronchoscopic lung volume reduction coil treatment of patients with severe heterogeneous emphysema. Chest. 2012 142(3):574-82.

27 Palamidas AF, Kemp SV, Shen M, McNulty W, Zoumot Z, Hopkinson NS, et al. Putative mechanisms of action of endobronchial coils Am J Respir Crit Care Med. 2017 Jul;196(1): 109-15.

28 Klooster K, Ten Hacken NH, Franz I, Kerstjens HA, van Rikxoort EM, Slebos DJ. Lung volume reduction coil treatment in chronic obstructive pulmonary disease patients with homogeneous emphysema: a prospective feasibility trial. Respiration. 2014;88(2):116-25.

29 Makris D, Leroy S, Pradelli J, Benzaquen J, Guenard H, Perotin JM, et al. Changes in dynamic lung mechanics after lung volume reduction coil treatment of severe emphysema. Thorax. 2018 Jun;73(6):584-6.

30 Hartman JE, Boezen HM, Heintzbergen S, De Greef MH, Klooster K, Ten Hacken NH, et al. Daily physical activity after bronchoscopic lung volume reduction: a pilot study. Eur Respir J. 2012;40(6):1566-7.

31 Biener L, Skowasch D, Hollmann S, Schreiber T, Nickenig G, Fimmers RPC. Endoscopic lung volume reduction in COPD: the impact of coil implantation on patients' physical activity. Respiration. 2020;99(2):177-80.

32 Lador F, Hachulla AL, Hohn O, Plojoux J, Ronot $\mathrm{M}$, Montet X, et al. Pulmonary perfusion changes as assessed by contrast-enhanced dual-energy computed tomography after endoscopic lung volume reduction by coils. Respiration. 2016;92(6):404-13.

33 Herth FJF, Slebos DJ, Criner GJ, Valipour A, Sciurba F, Shah PL. Endoscopic lung volume reduction: an expert panel recommendation: update 2019. Respiration. 2019;97(6):548-57. 